\title{
Pesniška samorefleksija v poeziji Primoža Čučnika
}

\author{
Mateja Eniko \\ Fakulteta za humanistiko, Univerza v Novi Gorici \\ School of Humanities, University of Nova Gorica \\ mateja.eniko@ung.si, mateja.eniko@gmail.com
}

Pesniška samorefleksija oziroma metapoezija obsega premisleke, povezane s poezijo in pesnikom kot ustvarjalcem. Interpretativna analiza metapoezije v pesniških zbirkah Primoža Čučnika (1971) pokaže, kako se v literarnih podobah zrcalita vloga poezije in položaj pesnika v kontekstu spremenjenih zgodovinskih in duhovno-literarnih okoliščin. Čučnik v avtotematskih pesmih reflektira odnos do pesniškega poslanstva in poezije, razmišlja o viru navdiha, intertekstualnih odnosih, poeziji kot odzivu na družbeno dogajanje, jeziku in ustvarjalnem procesu. S pesniško samorefleksijo pesnik utemeljuje poezijo in sebe kot ustvarjalca ter se umešča v literarni in družbeni kontekst.

Ključne besede: Primož Čučnik, mlada slovenska poezija, samorefleksija, metapoezija, družbeni kontekst

\section{Poetic Self-Reflection in the Poetry of Primož Čučnik}

Poetic self-reflection or metapoetry deals with considerations associated with poetry and the poet as the creator. The interpretative analysis of metapoetry in the works of Primož Čučnik (1971) shows how the literary images mirror the role of poetry and the position of the poet in the context of changed historical and spiritual-literary circumstances. In auto-thematic poems Čučnik reflects the attitude to poetry and poetic mission, thinks about 
the source of inspiration and intertextual relations, about poetry as a response to social events, about language and creative process. With poetic self-reflection the poet justifies poetry and himself as a creator and positions himself in the literary and social context.

Key words: Primož Čučnik, young Slovenian poetry, self-reflection, metapoetry, social context

\section{Kratka teoretska osvetlitev}

Pesniška samorefleksija je pomensko enakovredna s konceptom metapoezije oziroma avtotematske poezije, $\mathrm{v}$ določeni točki pa se povezuje tudi s konceptom samonanašalnosti. V uvodu zbornika Self-Reflexivity in Literature je izpostavljeno, da je samorefleksija "tako odraz kot tudi osnovna zahteva moderne racionalnosti in samozavedanja« (Huber, Middeke, Zapf 2005, 7).

Metapoezija zajema širok razpon tem. Vključuje razmislek o pesniku in njegovi vlogi, ustvarjanju oziroma aktu pisanja, navdihu, pesnikovem odnosu do tradicije, pesniškem poklicu, literarnem življenju - položaju ustvarjalca v literarnem sistemu in širšem družbenozgodovinskem kontekstu, o poeziji oziroma (besedni) umetnosti nasploh, pesmi kot umetniškem delu, pesniškem jeziku, literarnih konvencijah in tudi refleksijo o branju ter pričakovanem bralčevem odzivu (prim. Weber 1971, 181; Juvan 1994, 278; 2000, 194-195; 2001, 46).

Metapoetski premislek ima lahko različne pojavne oblike: obsega celotno pesemsko besedilo in je njegov ključni konstitutivni element ali pa gre le za drobec, ki je umeščen med druge motive. Pomembno pripomore $\mathrm{k}$ razumevanju osebne poetike in vloge literarnega diskurza v širšem družbenozgodovinskem okviru, hkrati pa pesniku omogoča samoosmišljevanje pesniškega dejanja, samoutemeljevanje v literarnem sistemu in samoumeščanje poezije $\mathrm{v}$ širši družbeni kontekst. S stališč sistemske teorije je samorefleksija strategija, $s$ katero se sistem literature samoregulira in odziva "na idejne, vrednostne, politične, gospodarske in socialne spremembe» (Juvan 2001, 46).

Eva Müller-Zettelmann se $\mathrm{v}$ obravnavi metapoezije naslanja na spoznanja naratologije in kot estetski učinek lirične samorefleksije oziroma avtoreferencialnosti izpostavi deziluzijo (preizpraševanje razmerja med 
resničnostjo in fikcijo). ${ }^{1}$ Avtorica uvede klasifikacijo, ki razlikuje med primarnimi in sekundarnimi metaliričnimi pesmimi. Pri sekundarni metaliriki gre za tematsko obravnavo posameznih vidikov literarne komunikacije, medtem ko je za primarno metaliriko ključno, da osvetljuje svojo lastno literarnost, njena značilnost je nemožnost razločevanja med aktom (dejanjem) in objektom tekstualizacije, iz paradoksa neskončnih izmenjav v tem hierarhičnem odnosu pa izvira estetski učinek razblinjanja iluzije (2005, 132-137).

\section{Družbene okoliščine in literatura}

Položaj literature in vloga literarnega ustvarjalca se spreminjata skladno z družbenimi spremembami. Za uveljavitev literature kot »samostojnega in zapletenega družbenega podsistema« je pomembno obdobje romantike, ko literatura dobi »vlogo nadomestka za izgubljeno totaliteto religije«, umetnik pa postane "subjekt svobodne in neizčrpne imaginacije» (Juvan 2001, 44). Do romantičnega genija, ki je zaradi nasprotja med nedosegljivim idealom avtonomnosti in izvirnosti ter neizogibno vpetostjo v družbeni kontekst paradoksen, so vodile spremembe vloge avtorja od antičnega pevca - vidca, prek srednjeveškega avtorja, čigar "avtoriteta se opira na Boga ", in profesionalnega pisca, ki se pojavi z razvojem tiska in trga (Dović 2007, 20-28).

$\mathrm{V}$ 20. stoletju umetniki dobijo bolj avtonomen, vendar socialno bolj negotov položaj, saj se upirajo nastajajoči množični družbi, veri v napredek in iztrošeni, nepristni podedovani tradiciji. Po Adornovi teoriji avantgardne umetnosti je značilnost sodobne umetnosti poleg proizvodnje umetniških del tudi problematiziranje položaja umetnosti in umetnika $\mathrm{v}$ svetu (Vattimo 2004, 94). Resnejši krizi je bila »romantična ideologija « v smislu poveličevanja pesnikov in literature kot nosilke družbenih vrednot tako izpostavljena šele konec 20. stoletja (Juvan 2001, 68).

Spreminjanje položaja literature in literarnega ustvarjalca $\mathrm{v}$ širšem kontekstu se reflektira tudi v literarnih delih. ${ }^{2} \mathrm{~V}$ slovenski poeziji je sam-

1 Primerjaj pri Horstu Breuerju, ki, ki kot značilnost metaliterature izpostavi sklicevanje na umetniško-fikcijski pogoj. To ožjo definicijo metaliterature v nadaljevanju razširi z ugotovitvijo, da metapoezija obsega besedila, v katerih je samosklicevanje strukturna značilnost, prek katere na paradoksen način obravnavajo lasten poetični status, obenem pa tudi besedila, ki tematizirajo verzno umetnost in posebnosti pesniškega poklica $(2005,49-50)$.

2 Metapoetično stanje lirike je še posebej značilno prav za moderni in postmoderni čas (Breuer 2005, 49-51). 
opremislek pesniškega ustvarjanja in pesnika kot ustvarjajočega subjekta moč slediti vse od začetkov slovenskega umetnega pesništva (Juvan 1994) in nato romantične težnje po uveljavitvi avtonomije pesništva, izražene v Prešernovih avtotematskih pesmih (Juvan 2001).

Podobno kot je imela književnost za večino evropskih narodov v romantiki narodnobuditeljsko vlogo in pomembno mesto pri »oblikovanju nacionalnih držav«, je bil tudi proces slovenskega osamosvajanja v devetdesetih letih »odvisen prav od 'kulturnega kapitala slovenske literature' kot osrednjega toposa nacionalne identifikacije« (Virk 2008, 3-4). Primož Čučnik opozori, da v Sloveniji sicer ni "politične poezije, kot jo poznajo na Poljskem v osemdesetih«, so pa avtorji v devetdesetih javno politično nastopali (Krečič 2005, 13). Spremenjene družbeno-politične okoliščine po osamosvojitvi Slovenije in po vzpostavitvi demokratičnega političnega sistema ter pluralnosti misli v družbi tako spodbujajo premislek o (novi) vlogi pesnikov (literatov) in poezije (literature) v družbi. Poezija je namreč izgubila samoumevno upravičenost do obstoja, ki jo je kot »manifestacija svobode« imela v enopartijskem sistemu (Kos 2004, 195-197).

\section{Samorefleksija v poeziji Primoža Čučnika}

Primož Čučnik (prvenec Dve zimi, 1999) se uvršča v mlado slovensko poezijo, ${ }^{4}$ to je skupino pesnikov, ki je začela ustvarjati po letu 1990. Je uveljavljen in večkrat nagrajeni avtor.' Njegov pesniški opus obsega sedem samostojnih pesniških zbirk, piše kritike in eseje, je tudi urednik. Avtopoetskim premislekom namenja prostor tudi v intervjujih.

V Čučnikovi avtotematski poeziji, ki je najmočneje prisotna v prvih treh in zadnji zbirki, najdemo premisleke odnosa do lastnega poslanstva in poezije, refleksije intertekstualnih navezav ter razmerja med pesniškim navdihom in obrtniško veščino. Pogosta so razmišljanja o ustvarjalnem procesu in jeziku kot mediju pesniškega ustvarjanja. ${ }^{6}$ Značilnost Čučnikovega dojemanja poezije je povezanost z zvokom, glasbo.

Matevž Kos izpostavi, »da je bila slovenskost - če sploh - prežeta z duhom poezije toliko časa, dokler je bila dejanskost države hipotetična, [...] zadeva pesniškega imaginarija $(2004,203)$. Prešernovega sklada (2008), Jenkova nagrada (2011) in Veronikina nagrada (2012).

6 Jezik je pomemben element Čučnikovega razmišljanja o poeziji tudi v intervjujih. O »visokem jeziku« poezije pravi, da je »bilo treba sestopiti. Poezija se oplaja z najrazličnejšimi jeziki« $(2012,231)$. 
Poetološka tematika je prisotna tudi v povezavi $\mathrm{z}$ odzivom poezije na družbeno dogajanje. $\mathrm{V}$ navezavi s tem se odpira dilema, v kolikšni meri je poezija lahko družbeno dejavna in ali je s stališča pesnika to pomembno.? $\mathrm{O}$ »specifičnem pojmovanju avtorjeve pozicije v odnosu do družbe« v mlajši slovenski liriki je pisal M. Potocco (2010, 234). Ugotavlja, da lahko pri Čučniku in nekaterih drugih pesnikih mlajše generacije $\mathrm{v}$ »Zavračanju povezave avtorja in njegovega delovanja v družbenem polju« prepoznamo »boj za simbolni kapital « in - v primerjavi z modernistično težnjo po avtonomnosti literature - vzpostavljanje »avtonomnost[i] avtorja kot konkretnega akterja v družbenem polju«. Potocco hkrati opaža, da se v zadnjih letih pri Čučniku na primer v zbirki Delo in dom - pojavlja »nastavek v smer družbene kritičnosti« (2010, 235). Prav željo po večjem deležu angažirane literature in obenem previdnosti v delovanju angažiranih avtorjev je Čučnik izrazil tudi na okrogli mizi festivala Pranger (Krečič 2005, 13). ${ }^{8}$

\section{Odnos do poezije in poslanstva pesnika}

V prvencu Dve zimi (1999) se lirski subjekt ustvarjanja loteva entuziastično, čeprav se zaveda, da ga čakajo tako napori kot ustvarjalnega zaleta polni trenutki, kar antitetično izrazi z verzi: »ko bom prisiljen žgati glino / in lepiti razbiti vrč« nasproti »ko bom barval stene prostora, / meril in polnil, se napil / in spravljal v ravnovesje«. Subjekt je pripravljen tudi na odpoved, saj njegovi "precizni prsti [...] zase ne zahtevajo ničesar« v želji doseči edinstveno: »Biti dotik jezika / na nebu / nemih ust« (Mera, 25). Ustvarjanje je poslanstvo spregovoriti z jezikom v območju nemega, njegova vera $\mathrm{v}$ učinek je neizpodbitna. Pesem ima moč in pravico prebiti polje molka, ker je utemeljena $\mathrm{v}$ tradiciji in nenehni ponovljivosti: "Zgodba / neštetih pesmi se ponavlja«, ter usojenosti govorečega in sprejemajočega: »potem postane / usoda in nazadnje hladno / upanje«. Drugoosebni govor lirskega subjekta, splošnejši »ti«, odpira dialog z naslovnikom, bralcem in izraža, da je govorec pesmi lahko vsak in da je pesem vseprisotna v vsakem posamezniku: »Poveš jo pri odprtem oknu.« Pesem pa ni le vpisana kot usoda v posameznika in čas, ampak ima funkcijo, ki sega čez estetsko razsežnost, prodre v globino posameznika: „Najprej se dotakne kože, / potem zaskeli in nazadnje / rahlo peče« (Pesem, 47). Metafora stopnjevane bolečine vnaša po-

7 Čučnik razmišlja o možnosti »drugačnih angažiranosti, ožje družbenih, mikropolitičnih, osebnih» $(2012,245)$.

8 Prim. Potocco $(2010,235)$. 
men katarzičnosti, nečesa, kar spoznavno-etično pretrese posameznika v samem jedru.

Biti kot ustvarjalec medij poetičnega izraza pomeni sprejeti ambivalentnost občutenj, izraženih skozi antiteze: »Besede so muka in dar. Zmaga in poraz. / Edino in odveč.» Poezija ustvarjajočega posameznika spremeni, do skrajnosti izostri zaznavanje: »Poezija je iz mene naredila / pošast « in omogoči subjektu, da se razcepi, dobi dvojnika in začne sprejemati sebe samega in svojo resnico z zunanjega gledišča: »To je moje drugo življenje, prestopil sem samega / sebe«, kar pa omogoči skrajno zmožnost spoznanja: "Živeti pesniško povzema vsa razpoloženja «(Spoznanje, 67). Poezija je tisti način govora in spoznavanja resnice, ki lahko zaobseže celoto, vse sinhrono in diahrono prisotno: »Preprosto hočem biti zraven, ko se rojeva, / novo in novo, [...] Tako resnično je tako resnično!« (Pesem Ortonimu, 51-52).

Lirski subjekt se zaveda, da poezije ne more definirati z enoznačno trditvijo, zato o njej razmišlja v pogojniku: »Če je poezija zato, da smo si bliže, [...] Če je poezija zato, da postane rob življenja«. Poezija naj bi na eni strani zbliževala posameznike in na drugi razširjala obzorja, možnosti, do koder lahko seže (duhovni) pogled človeka, ker prek poezije "postavljamo vprašanja nebu, / zemlji in bogovom«(Ostanki dneva, 57).

Antitetično razumevanje bistva in smisla poezije ter njena zmožnost zaobseči vse nianse med skrajnostmi se nadaljuje v zbirki Ritem $v$ rôkah (2002), v kateri je poezija nekje med žalostjo in smehom, med besedo in tišino ter med sovraštvom in ljubeznijo. Pesem postane za lirski subjekt pribežališče, kjer v risu samosti lahko sreča samega sebe in se začne razpletati kot »majhna zagonetka«: »Ko ti nekaj ne pusti zaspati / je edini prostor v pesmi«. V tem izpraznjenem, irealnem prostoru se pokaže možnost relativizacije časa: »kraj za zdaj in vedno« $(\mathrm{Za}$ G., 50).

$\mathrm{V}$ Akordih (2004) razmislek o poslanstvu pesnika izhaja iz primerjave s filozofom. Pesem Zakaj nisem filozof (62-63) je nastala kot odgovor na recenzijo, ki je Čučniku očitala, da je njegova pesniška zbirka Ritem $v$ rôkah v primerjavi s poezijo O'Hare, s katero se Čučnikova poezija intertekstualno povezuje, abstraktno refleksivna in da je Čučnik v njej bolj filozof kot pesnik (Divjak 2002). Čučnik se je zato odzval v obliki citatne navezave na O'Harovo pesem Zakaj nisem slikar, s čimer je zavrnil vnaprejšnje vkalupljanje poezije, ki je dialog in ne primerjava $z$ drugim in jo je sam razumel kot nekaj večjega od sebe $(2002,156)$. V pesmi je razložen proces pisanja, ki je na meji razumsko doumljivega: »Besede me preganjajo. Popravljam. Ne razumem, kaj hočem povedati« in tematizirana želja ubesediti tudi nerazum- 
ljivo - na primer zavedanje niča. Vendar ima tudi poezija tako kot filozofski diskurz: »'Od PRAZNINE so ostale le natisnjene besede'«, omejitve. Avtoreferencialna izpostavitev »napišem POLNI STAVKI NIČA« ponazarja paradoks, da »niča« ni mogoče izgovoriti ali napisati, ker akt poimenovanja izhaja iz prisotnosti.

Od spoznanja, da poezija ne more poimenovati v celoti vsega, kar subjekt pretresa, v predzadnjih dveh pesniških zbirkah (Delo in dom, 2007; Kot dar, 2010) razmislek o poeziji postane humorno-ironično obarvan. Vprašanje "Ali še verjameš v poezijo? « je ironično opredeljeno kot »Dobro vprašanje.« $\mathrm{V}$ nadaljevanju sledi zavrnitev iskanja pragmatične vloge poezije: »Način za preživetje, ohranitev vrste, / družbeno spremembo ...? / Nič takšnega.« Kljub temu izpostavljeni glagol biti ne dopušča dvoma o možnosti in smislu njenega obstoja. Poezija je umeščena med konkretnimi »črkami« in »nebom « - je nekaj stvarnega, ki omogoča vpogled v presežno, ki sega čez posameznika tukaj in zdaj, $v$ transcendentno. V sklepu refleksijo o vlogi poezije prekine avtoreferencialna navezava na postopek lastnega pisanja, pomensko zoženega na povsem tehnično raven, celo zgolj na napako stroja, neodvisno od hotenj subjekta.

\section{. (Pika)}

Napaka na pravkar kupljenem ekranu.

Izpostavitev tehničnega postopka stopi $\mathrm{v}$ semantično napeto razmerje $\mathrm{z}$ retoričnim vprašanjem o umestitvi poetičnega ustvarjanja $\mathrm{v}$ polje duhovnega: "Sfera sanj? «(Kaj je poezija, 30, Delo in dom). ${ }^{9}$ Lirski subjekt se zaveda nezmožnosti enopomenske opredelitve poezije. ${ }^{10}$

Rdeča nit Mikada (2012) je povezanost poezije z igro in zvokom, vendar ne v smislu lahkotnosti, poenostavljanja, temveč predstavljata osnovni kompozicijski in spoznavni načeli. ${ }^{\text {II }} \mathrm{V}$ igri kot metafori za poezijo si sam, zato ni prostora za tekmovalnost, vrednosti posameznih enot (pesmi) pa

9 Avtoreferencialne navezave, kot je na primer opredelitev "Območje: Lirika» (Weimarska republika, po letu 1919, 45, Kot dar), izpostavljajo fikcijskost napisanega in učinkujejo v smeri deziluzije; po E. Müller-Zettelmann bi lahko te pasaže uvrstili v primarno metaliriko.

10 Prim. s pesmijo Navodila za uporabo (31, Delo in dom).

11 Pomen toposa glasbe v Čučnikovi poeziji odražajo že naslovi nekaterih zbirk (Ritem $v$ rôkah, Akordi). Motivi, povezani z glasbo, so pogosti tudi v navezavi na poetološko tematiko. Zvoki, ki jih srečuje subjekt, so dražljaji za ustvarjanje poezije, prek motiva ušesa pa je poudarjen pomen vključitve več čutil za pravo spoznanje, kar omogoča 
so relativne. Pesnik poudarja, da igro - poezijo - lahko razume vsak in da je najboljša (doseže svoj cilj) tedaj, kadar je brezkončna - fingira ali ciklično ponavljanje ali neomejeno nadaljevanje. V Eseju o ušesu na koncu pesniške zbirke pesnik na kompleksen, pa tudi humoren način opredeljuje poezijo in neizogibno povezanost lastne osebe s pesniškim ustvarjanjem: »Imeti ušesa in posluh, zato da bi živel pesniško, to mi je namenjeno.« (109) Poeziji priznava avtonomnost, neodvisnost od ustvarjajočega subjekta in ne pristaja na njeno zgolj mimetičnost: »Poezija je odrasla in ima svoja čustva [...] Ne verjamem, da je treba čustva iz življenja prepisovati v poezijo.« (109) Vrednost in pomen poezije vidi v njeni zmožnosti, da prek sinestetičnega dojemanja posamezniku omogoči zavedanje sveta izven razumsko dosegljivih meja: »Ekonomija poezije je izguba zavesti. Je dobiček zavedanja.«(113)

\section{Od navdiha do obrtniške veščine}

Ustvarjajoči pesniški subjekt v Dveh zimah priznava navdih in ustvarjanja poezije ne razume kot (le) priučeno veščino. Ustvarjalna moč ni absolutna, je ranljiva in tudi odsotna: »Zdaj ni več tistih pisem, juter in navdiha«. Subjekt pa ni božansko navdahnjen romantični pevec, temveč navdih odkriva v stvarnosti, ki ga obdaja: v vsakdanjih podobah življenja, spominih in naravi ter podobah mesta. Natančno opazovanje in moč pretanjenega spominjanja, ki subjekt vodita $\mathrm{v}$ ustvarjanje, povzročita njegovo drugačnost od drugih: "In razen mene, ki čakam pesem, vsi čakajo poletje« ter globlje, trpko zavedanje odtekanja časa, zato je subjekt »edini, ki presekan s časom šteje kope posušenih let« (Basina, 39). Vprašanje ustvarjalnih možnosti je vpeto $\mathrm{v}$ širšo eksistencialno negotovost. Razrešitev eksistencialne in ustvarjalne otrplosti pa pesniški subjekt vidi v srečanju $\mathrm{z}$ »drugim človekom «, čeprav s tem determiniranost s smrtjo ostaja (Ledena gora, 83).

Zavedanje časa prek cikličnega menjavanja letnih časov in raziskovanje možnosti, da pesem njegovo odtekanje ustavi, se zrcali v Prihodih zime, 2.: »Pesem je (pravi) trenutek, odločen, da ostane« (40, Ritem v rôkah). Odvisnost pesnjenja od zunanjega sveta in poetično odsevanje (mimesis) realnosti je ironičnemu podtonu izpostavljeno v Sonetih za neodgovorjene klice, 3.: »Le kako bi človek pisal, če bi se / preselil v Ljubljano? Mogoče kot dež, padajoč [...] Kot črnogledi pesniki, // ki

poezija. Glasba obenem ni le metafora poetičnega ustvarjanja, ampak je tudi širši eksistencialni simbol življenja. 
te zmeraj opominjajo, da bo treba umreti« (46). Lirski subjekt se upre temačnemu eksistencialnemu razpoloženju in modernistični pesniški tradiciji in za svoje ustvarjanje namesto stalnega premišljanja o neizbežnosti smrti $\mathrm{v}$ prizmi sprijaznjenja $\mathrm{z}$ neizbežnim izbere življenje $\mathrm{v}$ vsakodnevnih opravkih: »Preveč kaditi, popiti preveč / kave in vse do konca tragično kramljati s tabo.«

V pesniški zbirki Kot dar je navdihovanje ob cikličnih spremembah narave, $v$ katerih je vkodirano stalno gibanje, podvrženo ironiji. Pretirano navdušen opis prebujanja pomladi "nič s pomladjo se ne meri po lepoti« dobi zvrstno ambivalenten odgovor v grobi banalizaciji »skopneli kupi dreka, znani po svoji grdoti« (Zgodnja pomlad, Hopkins, 14). Odmik od romantično patetične vzhičenosti nad naravnimi procesi vodi v poudarjanje pomena ustvarjalčeve udeleženosti $\mathrm{v}$ aktualnih družbenih dogajanjih, pri čemer ne gre spregledati ironičnega podtona: »Kar razburljivo je bilo / opazovati demonstrantsko množico [...] Od tu bom sigurno odšel / s polnim jezikom podrobnosti«. Z metaforo ptiča, ki »nekako gnezdi v glavi / leti samo takrat, ko komu poje«, je pesnik opredeljen kot nekdo, ki lahko s ptičje perspektive (distance) govori o svetu, hkrati pa se z uporabo narekovajev distancira od »'večnih stvari'«, ki jih »čivka«. ${ }^{\text {I2 }}$ Pesem naj bo razumljiva, tukaj in zdaj (Da zaprem to mapo, 32). Pesniški subjekt podobe črpa iz avtentičnega življenja slehernikov, njihovemu govoru daje prostor $\mathrm{v}$ pesmih, s čimer dobijo značilnost večglasnosti. Subjekt se tudi zaveda, da je del moderne, tehnološke družbe, ki se je korenito (tudi vrednostno) preobrazila. Kot ustvarjalec se mora prilagoditi: »opazujem proizvode, vedoč, / da so jih naredile podobne roke kot moje / in stroji, podobni pisalnim strojem, / računalniki, podobni mojemu «. Pesnik in njegova tradicionalno duhovno privilegirana dejavnost postaneta del kapitalistične družbe: »Če sta mi bila, v kakršni koli meri, dana duša in talent, o tem ne vem ničesar. [...] Tako si mislim, ko se nasmiham / izza pulta svoje prodajalne« (Trgovina, 54) in »razumem, da sem tudi sam obrtnik« (Dobra zgradba, 56). Talent, izbranost v novem kontekstu nista več pomembna. Pisanje se ne odvija več le $\mathrm{v}$ »sferi sanj«, ampak tudi na računalniku - z rokami, ki delajo tudi vsa druga bolj ali manj praktična opravila.

12 Podoben učinek ima koncept dvojnika v Dveh zimah, ki subjektu omogoča distanco in avtorefleksivno introspekcijo: »Dvojnik, si samo privid jezika, / sestavljen le zato, da se učim / pomena besed?« (Dvojnik, 19). 


\section{Samorefleksija intertekstualnega dialoga}

Prepletenost ustvarjajočega subjekta $\mathrm{z}$ literaturo se kaže $\mathrm{v}$ motivu branja kot spodbude za pisanje, še posebej v zbirki Akordi.

Pomenska večplastnost Čučnikove poezije pa pogosto temelji na prepletenosti s citati in vključevanju različnih diskurzov tako iz literarnega polja kot tudi iz vsakdanje komunikacije: »pravi tvoj hitri odgovor [...] in to je čisto dovolj za napisat / tole pesem " (59, Ritem v rôkah). ${ }^{13}$ Prek intertekstualnega dialoga, ki je večkrat tudi eksplicitno izpostavljen s kazalkami, kot so naslovi, moti, posvetila, pesniški subjekt posreduje tudi metapoetične refleksije. Čučnikova poezija stopa v produktivno interakcijo še posebej z ameriško in poljsko pesniško tradicijo. Sam Čučnik pravi, da ga je ameriški pesnik O'Hara »naučil predvsem tega, kako pesem najde živ prostor med dvema osebama « $(2012,233)$. Čučnikov literarni dialog z O'Haro se kaže že v nekaterih temeljnih poetoloških usmeritvah, kot je produktivno povezovanje poezije $z$ glasbo in tudi vizualnim. ${ }^{14}$ Skupno je njuno navdihovanje nad pesniškimi imeni, kot je na primer Majakovski. ${ }^{\text {IS }}$

V Čučnikovi poeziji se prek citatnosti, dvogovora s pesniškimi glasovi, kot so na primer Ashbery, Majakovski, že omenjeni O'Hara, vzpostavlja večpomenskost besedil, živo interakcijo z drugimi besedili pa pesnik tudi tematizira kot eno pomembnih prvin pesniškega postopka in odnosa do pesniškega ustvarjanja. V Čučnikovih pesmih je zavestno tematizirano, da pesniški subjekt - avtor ni le prejemnik vpliva, ampak da dejavno vstopa v intertekstualna razmerja in se nanje odziva. Pesem Majakovski tako izraža naklonjenost, ampak sočasno tudi razdaljo subjekta do pesniškega predhodnika: »ker ljubim tvoj oblak / in se zaljubim v tvoj šal / ampak ne vate / klovna zgodovine« (39, Akordi).

V prvencu Dve zimi pesnik eksplicitno razkriva navdihovanje svojega pisanja pri pesnikih, kot sta Vallejo in Miłosz. ${ }^{16}$ Pesniški subjekt se z eksplicitno izpostavljenim citiranjem Miłosza izreka o svoji poetološki

13 Čučnik izpostavi, da pri pisanju želi najti izviren izraz, vendar da hkrati občuti vpetost v (jezikovne) vzorce tradicije (2012: 231).

14 Čučnik je prepoznaven po literarno-glasbenih nastopih in odpiranju prostora literarne umetnosti elementom drugih umetnosti, na primer vizualnim in zvočnim v Odi na manhatnski aveniji. Poseben primer prepletanja jezikovno-vizualnega sporočanja je tudi projekt Ljubezen je bojno polje, pri katerem je vzporedno z razstavo v galeriji Škuc (Čučnik, Kariž, Ožbolt 2005) nastala tudi knjiga (2006).

15 O O'Hari, njegovi povezanosti z drugimi umetnostmi in literarnimi spodbudami Čučnik piše v spremni besedi k izboru pesmi Srce v žepu (2002, 99-107).

16 Citata iz njune poezije stojita kot moto na začetku zbirke. 
poziciji: "In še to kar pravi Miłosz: Who serves best doesn't always understand." in »Največ pesmi ne razumem. [...] Samo iz ljubezni je možna pesem« (Pismo, 27). Citat potrjuje stališče, da je pesem diskurz, v katerem ni možno in niti ne nujno popolno razumevanje. Pomembno za pesniško ustvarjanje pa je, da izhaja iz odnosa do drugega, do sveta. $S$ poezijo perujskega pesnika Valleja se pred lirskim subjektom razprejo nianse trpečega občutenja sveta, zato si zanje dovoli odpreti tudi svoje ustvarjanje: »Kadar koli srečam Valleja, se skorja mojega / pisanja vrne v zibelko, tisto največ, kar sem preživel [...] in vrne se moja patetična žalost«. Vrnitev k izvoru, h koreninam razpre eksistencialno tesnobo zavedanja končnosti, $\mathrm{v}$ risu katere je ujeto tudi ustvarjalno dejanje: »potem / lahko razumem, kaj pomeni poznati konec, // vseskoz pisati v senci točnega sla (Srečanje, 9). Vzporednost eksistencialne pretresenosti in razsežnosti dilem ustvarjanja je izražena tudi v pesmi Edvardu Kocbeku: »Vedno začenjamo / znova. Samo jecljamo še« (77).

Pesniški subjekt najde identifikacijo glede razumevanja postopka pisanja kot truda $\mathrm{v}$ intertekstualnem navezovanju na Jesihove verze iz zbirke Soneti, ko pravi, »da si ves preljubi dan grizem nohte / in se mučim $\mathrm{z}$ eno samo vrstico « (Musica vulgaris, 6o, Akordi). Tudi Jesihov pesniški subjekt izpoveduje pomanjkanje navdiha in ustvarjalni mrk, obe pesmi pa prežema blaga humorna ironija, ki preizprašuje možnosti poiskati in poimenovati vir poetičnega navdiha ter potrjuje, da je pesniški postopek vedno tudi trdo delo in interakcija $\mathrm{z}$ drugim in drugimi besedili.

Srečevanje Čučnikove poezije $\mathrm{z}$ ameriško megalomanskostjo in občutje bližine s poljsko poezijo zasledimo v pesmi Amerika (10, Ritem $v$ rôkah): »Amerika, / pol toliko mi nisi dala kot daješ poljskim pesnikom.» Eksplicitno je tematiziran intenziven odnos med pesniškim subjektom in vsem, kar se ga je dotaknilo v Ameriki, vendar ostaja samozavesten v svoji poziciji, zavedajoč se, da so odnosi vedno dvosmerni: »Nisi mi dala veliko in še to ti vračam."

Intertekstualno sklicevanje na O'Haro, izpostavljeno že $\mathrm{v}$ povezavi z literarno polemiko Zakaj nisem filozof, je tudi pesem Hotel Transilvanija (Nova okna), kar kaže že istoimenski naslov. Čučnik prek navezovanja odgovarjanja - na O'Harovo pesem, ki ima obliko dialoga prvoosebnega pesniškega subjekta $\mathrm{z}$ drugoosebnim "you «, tematizira medbesedilno povezanost množinskega subjekta $\mathrm{z}$ drugimi besedili: »česar se spomnimo, ko smo / bili starejši ali mlajši, [...] bilo je črnilo / mračnih črk, nismo vedeli, ali sanjamo« (63). Znotraj medbesedilnega dialoga, »v katerem je izbi- 
ra branj za vsakogar«, je čas relativiziran. Pesniški subjekt prek spletanja intertekstualnih vezi vpeljuje večpomenskost svoje refleksije o življenju, bližini z drugim, preseganju časa: »ampak odbitih v ogledalih, / kjer se vidi, da ne tkemo sanj in nismo / nesmrtni« (66) in želji po dosegi estetskega: »Tu je vse v čakanju / na lepoto« (65).

Ashbery s svojimi verzi je izhodišče za odkrivanje pesniškega postopka - ustvarjanja -, ki je znova umeščeno v območje sanj, predstav. Pesniški subjekt fingira spomin (sanje), ki ni njegov pravi spomin, saj izhaja iz intertekstualne navezave - citatnega dialoga - s pesmijo Ashberyja The Instruction Manual. Podoba Priročnika za sanje, kot je naslovljena Čučnikova pesem, lahko simbolizira pesmi, ki pesnika spodbudijo za njegovo lastno ustvarjanje: »Ponujajo se sanje in razblinjajo. [...] Zdaj bom izstopil in vrnil se bom k priročniku, ki me je pripravil sanjariti o tramvaju v Ljubljani« (17, Delo in dom). Vendar pisanje pesmi ne more biti nikoli zgolj tehnično nizanje citatov, naslanjanje na vplive, ustvarjanje na podlagi vnaprej pripravljenih navodil, priročnikov, ampak je živa interakcija, vedno tudi v polju imaginarnega, sanjskega in ne docela razumljivega.

V zbirki Kot dar tradicija ni tematizirana (le) kot vir navdihujoče interakcije, ampak subjekt eksplicitno izpostavi tudi željo po njenem preoblikovanju, kar čuti kot svojo odgovornost: "Mogoče ponoviti isto pesem, // ampak na nov način, preden se dobrave zmračijo / in ne bomo več našli nazaj« (Pastoralne skrivalnice, 22). Motiv ponavljanja že znanega pesnik podčrta s hkratno intertekstualno navezavo na pesem Josipa Murna Ko dobrave se mrače. Tematiziranemu občutju pritiska pa sledi subjektova odločitev za kreativni spopad s tradicijo, ples, ki je odraz kreacije, igre, energije in vere v svoje početje: »To je pritisk, / ljuba duša / lets dance« (Ars Poetica 2007, 71, Mikado). Humorno-ironično je ubesedeno tudi razhajanje s tradicijo modernistov (Proti modernistom, 96), kjer prek motiva ušesa lirski subjekt izrazi svojo neodvisnost in prehajanje v ustvarjalno zrelost, ki si poišče svoj način pristopanja do sveta - sinestetično dojemanje. ${ }^{17}$ $\mathrm{S}$ pogumnim izražanjem lastnega pesniškega kreda si poišče svoje mesto $\mathrm{v}$ literarnem polju in se samoumešča v nizu tradicije. Poleg soočenja in dialoga s tradicijo hkrati na več mestih v sproščenem slogu ubeseduje tudi svojo umeščenost v generacijski krog pesniških kolegov: »Škrjanec na čiku, Podlogar na čaju« (Kredo 2, 80). 


\section{Poezija - družba}

V prvencu si pesniški subjekt - ustvarjalec - zada za nalogo biti popisovalec, vendar $\mathrm{v}$ tej zbirki prednjačijo motivi in podobe iz narave, subjektovo intimno odzivanje nanje ter osebne čustvene prelomnice. V naslednjih dveh zbirkah se njegov fokus usmeri tudi v družbeno stanje. ${ }^{18}$ Posreduje kritičen pogled na sočasno potrošniško družbo, $\mathrm{v}$ kateri so $\mathrm{v}$ prednosti glasnejši in slepo lojalni oblastnim strukturam in tradicionalnim avtoritetam, ki narekujejo življenja ljudem in jim odrekajo svobodo misli. Pesniški subjekt razmišlja, da bi se lahko tudi sam skril v množico, saj si ne želi slave in bi bilo to zanj lažje. Vendar kljub prevladi neumnosti, zanikanju tisočletne kulture naše civilizacije, uklanjanju množic banalnostim kapitalizma, odpovedi svobodi sam čuti zavezo, da se upre: "v tvoji nabiti glavi / odmevajo preslišani glasovi« (Zidovi, 8-9, Ritem v rôkah). Vztraja v govorjenju, ker posoja glas tistim, ki niso slišani. Pesniški subjekt se prepoznava kot nosilec vrednot svobode, neodvisnega mišljenja, neuklanjanja avtoritetam in materializmu. ${ }^{19}$

Akordi izpostavljajo problematiko nasilja, ki je vkodirano v ne-nasilje, gre za dve plati iste pojavnosti, zato se zdi popolna odstranitev nasilja nemogoča. Ker gre za prepletenost, je distanciranje posameznika od sovraštva neiskreno, dvolično dejanje: »Sovražiš usta, ki sovražijo?« Vprašanje: »Kdo jo [puško] bo prvi vrgel. / Vojak, pesnik ali derviš.« izgubi svojo vprašalno funkcijo in postane trditev, ki sugerira neizbirnost, vnaprejšnjo določenost: "Ne jezik ne molitev ne ustavita, / od zmeraj tu kot eno rasteta / nasilje, ne-nasilje!« (Puška v koruzi, 53). Pa vendar prevladujoče razpoloženje ni obup. Poezija ostaja dejanje, ki se upira vdanosti v družbo nasilja, poziva $\mathrm{k}$ neobsojanju in neapatičnosti.

Pesmi, ki poetološko tematiko povezujejo $\mathrm{z}$ odzivom na aktualno družbeno stanje, je v pesniški zbirki Kot dar še več. Pesem Moje hortenzije (26) je premislek razmerja med jezikom, narodom, vrednotami (svobodo) in družbeno realnostjo. Lirski subjekt pod vprašaj postavlja koncepte (na

18 Čučnik v esejističnem razmisleku pravi, da se je umetnik zaradi zapletenosti stvarnosti usmeril v svoj notranji svet in eksperimentiranje $\mathrm{z}$ jezikom. Vendar sam zagovarja "težnjo po razumljivosti in preprostosti« in vztraja, da naj poezija podaja "celostno človeško doživljanje«, čeprav bi bilo verjeti v neposreden vpliv poezije na resničnost naivno $(2008,19-22,28)$.

19 Pesem Iščemo varuha, kje je (35, Delo in dom) prek intertekstualne navezave na znan Zajčev verz »Za vse boš plačal« pokaže, da so tisti, ki se ne uklonijo in ostanejo zvesti svojim vrednotam ter idealom, podvrženi nerazumevanju zbirokratizirane politično-družbene situacije. 
primer narod, tudi jezik kot »skupno zadevo«), ki so zgolj konstrukti, oblikovani skozi zgodovino, in ki jim brez premisleka verjamemo: "Narod je univerzalna množica posameznikov [...] Ali pa je to nacija. Ali pa je to država.« Kritična ost je usmerjena proti vzorcem mišljenja, ki nam jih vsiljujejo drugi, naši naivnosti in nasedanju konstruktom oblikovalcev splošnega javnega mnenja: »Kaj govorim, to je obdobje novega optimizma.« Osrednji tok ironično intonirane refleksije pa $\mathrm{v}$ slogu refrenskega odpeva prekinja naslovna podoba hortenzij: »Vsak pri sebi ve, kaj so njegove hortenzije. [...] Lep jezik zagatno zaliva [...] moje hortenzije.« Hortenzije lahko predstavljajo ideal, smisel človekovega življenja. »Hortenzije« pesniškega subjekta ostajajo povezane $\mathrm{z}$ jezikom in možnostjo estetskega jezikovnega izraza. ${ }^{20}$

V ciklu Zamisel reda $v$ zapuščeni kitajski restavraciji (Kot dar) avtoreferencialno ozaveščanje povoda za pisanje izpostavlja aktualno problematiko: »Tole sem začel pisati iz usmiljenja [...] Kot strela z jasnega sem pomislil / na družine priseljencev." (67) Pesnik poskuša s svojim ustvarjanjem vzpostaviti red, ki ga ni in za katerega se zaveda, da bo mogoč le na ravni literarnega. Gre le za »zamisel«, zato »[t]a red moraš zaključiti / z nasmeškom, in to je več, kot lahko / jeziki povejo« (75).

\section{Zaključek}

S samorefleksivnimi podobami se pesnik skladno $\mathrm{z}$ novimi okoliščinami samopozicionira v literarnem sistemu - v krogu sodobnikov in tradicije in s preizpraševanjem smisla in pomena poezije samoutemeljuje pesniško ustvarjanje v sodobni družbi.

Avtotematske podobe razkrivajo, da poezija ostaja za subjekt neulovljiva v smislu enoznačne definicije, vendar pa subjekt spreminja do skrajnosti in mu omogoči posebno spoznanje resnice, srečanje $s$ svetom in $s$ samim sabo. Kljub temu da subjekt odkriva tudi omejitve jezika in poezije, ne dopušča dvoma v smisel njenega obstoja. Poezija je nekaj stvarnega,

20 Refleksija o jeziku je prisotna na več mestih. Pesnik se zaveda odvisnosti pesniškega ustvarjanja od jezika: "Pesmi so iz besed" (19:47, 70, Ritem v rôkah). Subjekt utemeljuje sebe in svet prek jezika, določen je z njim, saj mu omogoča stik s svetom oziroma prek njega svet dojema in hkrati tvori. Kasneje jezik postavi na prvo mesto, izstopa tendenca po jeziku, ki bi bil neodvisen od subjekta in bi lahko govoril čez subjektovo posameznost. Osvobojen jezik je nosilec resnice. Ima pa tudi omejitve ne more poimenovati in s tem utemeljiti transcendence: »In beseda Bog se vzdiguje v nekaj, / kar v resnici je, ampak ne morejo je izgovoriti / usta" (Hvala za sonce, 58, Nova okna). Kljub temu pa vera v besedo - poezijo - ostane neomajna: »Kar koli se zgodi, imaš besedo" (Pozna pomlad, 16, Kot dar). 
ki omogoča vpogled v presežno. Pesnik ni od realnosti distanciran, božansko navdahnjen pevec, ampak išče navdih v življenju okrog sebe. Zaveda se, da je pisanje tudi veščina, in sprejema vpetost $\mathrm{v}$ realnost sodobne družbe. Svojo posebnost vidi v sposobnosti pretanjenega opažanja. Povezava poezije z glasbo, z zvokom oziroma slušnim se nazadnje izkristalizira kot pravi način spoznavanja in pesniškega ustvarjanja. Prek samorefleksije je podan tudi subjektov odnos do pesniške tradicije, ki prehaja od navdiha, interaktivnega povezovanja do želje preseganja vpliva in nazadnje v odločitev za samozavestno kreativno sodelovanje $\mathrm{z}$ njo.

Bolj kot razmislek odgovornosti poezije do tradicionalnega koncepta naroda je prisotno spraševanje o vlogi poezije in lastnega vztrajanja $\mathrm{v}$ ustvarjanju v kontekstu globalnih problemov sodobne družbe. Pesniški subjekt posreduje kritičen pogled na potrošniško družbo. Pomen svojega početja prepoznava $\mathrm{v}$ izražanju vrednot svobode, neodvisnega mišljenja in upora materializmu. Kot ustvarjalec daje glas neslišanim.

\section{Viri}

Čučnik, Primož. 1999. Dve zimi. Ljubljana: Aleph.

Čučnik, Primož. 2002. Ritem v rôkah. Aleph. Ljubljana: Center za slovensko književnost.

Čučnik, Primož, Gregor Podlogar in Žiga Kariž. 2003. Oda na manhatnski aveniji. Velika šerpa. Ljubljana: LUD Šerpa.

Čučnik, Primož. 2004. Akordi in druge pesmi. Žepna šerpa. Ljubljana: LUD Šerpa.

Čučnik, Primož. 2005. Nova okna. Prišleki. Ljubljana: LUD Literatura.

Čučnik, Primož. 2006. Sekira v medu: prebrane in druge pesmi: 1995-2005. Klasična šerpa. Ljubljana: LUD Šerpa.

Čučnik, Primož, Žiga Kariž in Alen Ožbolt. 20o6. Ljubezen je bojno polje: knjiga umetnikov = Love is a battlefield: artists book. Velika šerpa. Ljubljana: LUD Šerpa.

Čučnik, Primož. 2007. Delo in dom. Prišleki. Ljubljana: LUD Literatura.

Čučnik, Primož. 2010. Kot dar. Klasična Šerpa. Ljubljana: LUD Šerpa.

Čučnik, Primož. 2012. Mikado: (1-5-5-15-15). Beletrina. Ljubljana: Študentska založba.

Čučnik, Primož. 2015. Trilogija. Prišleki. Ljubljana: LUD Literatura. 


\section{Literatura}

Breuer, Horst. 2005. »ohn Keats' Ode 'To Autumn' als Metapoesie«. V SelfReflexivity in Literature, ur. Werner Huber, Martin Middeke in Hubert Zapf, 49-64. Würzburg: Königshausen \& Neumann.

Čučnik, Primož. 2002. »Zakaj nisem filozof Literatura 14 (136): 155-158.

Čučnik, Primož. 2008. Spati na krilu: eseji, kritike, fragmenti. Ljubljana: LUD Literatura.

Čučnik, Primož. 2012. "Zame se pesem vedno dogaja vsaj med dvema pesmima«. Spraševal je Igor Divjak. Literatura 24 (250): 228-246.

Divjak, Igor. 2002. »Intelektualne sheme namesto atmosfere«. Literatura 14 (135): 138-144.

Divjak, Igor. 2016. »Tretji Čučnikov obrat: Primož Čučnik: Trilogija«. Delo, 30. 8. 2016. 15.

Dović, Marijan. 2007. Slovenski pisatelj: razvoj vloge literarnega proizvajalca $v$ slovenskem literarnem sistemu. Ljubljana: Založba ZRC, ZRC SAZU.

Huber, Werner, Martin Middeke in Hubert Zapf, ur. 2005. Self-Reflexivity in Literature. Text \& Theorie. Würzburg: Königshausen \& Neumann.

Juvan, Marko. 1994. "Slovenski Parnasi in Eliziji: literarni kanon in njegove uprizoritve«. V Individualni in generacijski ustvarjalni ritmi $v$ slovenskem jeziku, književnosti in kulturi: ob 1o-letnici smrti Marje Boršnikove (Obdobja, 14), ur. Marko Juvan in Tomaž Sajovic, 277-315. Ljubljana: Znanstveni inštitut Filozofske fakultete.

Juvan, Marko. 20oo. Vezi besedila: študije o slovenski književnosti in medbesedilnosti. Novi pristopi. Ljubljana: Literarno-umetniško društvo Literatura.

Juvan, Marko. 200oa. Intertekstualnost. Literarni leksikon, 45. Ljubljana: DZS.

Juvan, Marko. 2001. »Prešernova in Puškinova poezija o poeziji«. V F. Prešeren - A. S. Puškin = F. Prešern - A. S. Puškin: $($ ob 2oo-letnici njunega rojstva $)=$ ( $k$ 2oo-letiju ih roždenija), ur. Miha Javornik, 43-71. Ljubljana: Znanstveni inštitut Filozofske fakultete.

Kos, Matevž. 1996. Prevzetnost in pristranost: literarni spisi. Novi pristopi. Ljubljana: Literarno-umetniško društvo Literatura.

Kos, Matevž, izbral. 2004. Mi se vrnemo zvečer: antologija mlade slovenske poezije: 1990-2003. Ljubljana: Študentska založba.

Krečič, Jela. 2005. »Politični pranger«. Delo, 13. 7. 2005. 13.

Müller-Zettelmann, Eva. 2005. »'A Frenzied Oscillation': Auto-Reflexivity in the Lyric«. V Theory into poetry: new approaches to the lyric, ur. Eva 
Müller-Zettelmann in Margarete Rubik, 125-145. Amsterdam; New York: Rodopi.

Novak Popov, Irena. 2003. Sprehodi po slovenski poeziji. Maribor: Litera.

O'Hara, Frank. 2002. Srce v žepu, izbor in prevod Tone Škrjanec in Primož Čučnik. Ljubljana: ŠKUC.

Obermaier, Sabine. 1999. "Möglichkeiten und Grenzen der Interpretation von 'Dichtung über Dichtung' als Schlüssel für eine Poetik mittelhochdeutscher Lyrik«. V Mittelalterliche Lyrik: Probleme der Poetik, ur. Thomas Cramer in Ingrid Kasten, 11-32. Berlin: Erich Schmidt.

Oraić Tolić, Dubravka in Viktor Žmegač, ur. 1993. Intertekstualnost \& autoreferencijalnost. Zagreb: Zavod za znanost o književnosti Filozofskoga fakulteta Sveučilišta u Zagrebu.

Paternu, Boris. 1999. Od ekspresionizma do postmoderne: študije o slovenskem pesništvu in jeziku. Ljubljana: Slovenska matica.

Potocco, Marcello. 2010. »Raba podobja in avtonomnost pesniške pozicije (nekaj opazk ob mlajši slovenski liriki)«. V Sodobna slovenska književnost (1980-2010) (Obdobja, 29), ur. Alojzija Zupan Sosič, 233-238. Ljubljana: Center za slovenščino kot drugi/tuji jezik pri Oddelku za slovenistiko Filozofske fakultete.

Vattimo, Giani. 2004. Filozofska karta 20. stoletja: tehnika in eksistenca. Ljubljana: Sophia.

Virk, Tomo. 2008. "Zakaj je književnost pomembna?« V Književnost v izobraževanju - cilji, vsebine, metode (Obdobja, 25), ur. Boža Krakar Vogel, 3-13. Ljubljana: Center za slovenščino kot drugi/tuji jezik pri Oddelku za slovenistiko Filozofske fakultete. 